OPEN ACCESS

Edited by:

Huisu Chen,

Southeast University, China

Reviewed by:

Ping Duan,

China University of Geosciences

Wuhan, China

Xiaoming Huang

Southeast University, China

*Correspondence:

Kaidi Liu

liukaidi1994@outlook.com

Specialty section:

This article was submitted to

Structural Materials,

a section of the journal

Frontiers in Materials

Received: 29 February 2020

Accepted: 08 June 2020

Published: 30 July 2020

Citation:

Chen F, LiU K, Tan Y, Ye S, Xu H and

Ouyang J (2020) Factors Influencing

the Interfacial Bonding Characteristics

Between Cold Patching Asphalt

Mixture and the Old Pavement.

Front. Mater. 7:208

doi: 10.3389/fmats.2020.00208

\section{Factors Influencing the Interfacial Bonding Characteristics Between Cold Patching Asphalt Mixture and the Old Pavement}

\author{
Fengchen Chen ${ }^{1,2}$, Kaidi Liu ${ }^{1,2 *}$, Yiqiu Tan ${ }^{3}$, Song Ye ${ }^{1,2}$, Huining $X u^{3}$ and Jian Ouyang ${ }^{4}$ \\ ${ }^{1}$ China Airport Construction Group Corporation, Beijing, China, ${ }^{2}$ Beijing Super-Creative Technology Co., Ltd., Beijing, China, \\ ${ }^{3}$ School of Transportation Science and Engineering, Harbin Institute of Technology, Harbin, China, ${ }^{4}$ Faculty of Infrastructure \\ Engineering, School of Transportation and Logistics, Dalian University of Technology, Dalian, China
}

Cold patching asphalt mixture (CPAM) has been widely used in pothole repair due to the advantages of convenient construction and easy storage. However, CPAM usually has a short service life because of insufficient bonding to the old pavement during service. Therefore, in order to ensure the good bonding of CPAM to the old pavement and improve the integrity and durability of pothole repair, this work carried out a study on the influencing factors of the bonding characteristics between CPAM and the old pavement. The oblique shear test was used as the research method with an evaluating index shearing strength. The influencing factors which affect the interface bonding characteristics, such as temperature, humidity, types of tack coat, the amount of tack coat spreading, and surface roughness, were compared and analyzed. The analysis results illustrated that the interface bonding characteristics are weak at high temperature and decrease with the increase of humidity. There exists an optimal binder spreading amount, where the denser the CPAM is, the smaller the spreading amount of the tack coat is. The groove on the old pavement can increase the bond strength of the interface, and there is optimal groove spacing. Based on this, the gray correlation analysis method was used to clarify the degree of influence of various factors and reveal the dominant factors that affect the interface bonding characteristics. The analysis indicated that the dominant influencing factors of the interface bonding characteristics are the type of tack coat and the roughness of the surface.

Keywords: cold patching asphalt mixture, influencing factors, interface bonding, gray correlation analysis, dominant factors

\section{INTRODUCTION}

A pothole is a common type of damage in asphalt pavement (Adlinge and Gupta, 2013; Kim and Ryu, 2014; Kim et al., 2017; Ouma and Hahn, 2017). Potholes seriously affect the driving comfort and safety, shorten the life of the pavement, and reduce the service level of the pavement. Therefore, the pavement should be repaired in a timely fashion after potholes appear (Dong et al., 2014; Zhang et al., 2014; Wang et al., 2015; Tedeschi and Benedetto, 2017). Currently, there are many kinds of materials used for pothole repair (Prowell and Franklin, 1996; Ouyang et al., 2019a, 2020). Cold patching asphalt mixture (CPAM) has been widely used in pothole repair 
because of its strong environmental adaptability, simple repair process, and convenient storage and transportation (Anderson et al., 1998; Li et al., 2010a; Zhao and Tan, 2010; Zhang et al., 2014; Diaz, 2016; Liao et al., 2016). However, the poor bonding performance between CPAM and old pavement materials is a common issue during application due to the differences in material composition, environment, and construction technology. The bonding performance between them seriously affects the service life and the durability of CPAM (Rosales Herrera and Prozzi, 2008; Tan et al., 2014; Rezaei et al., 2017).

Considering its particularity and the complexity in its service environment, the influencing factors of the interfacial bonding characteristics between CPAM and the old pavement are varied (Munyagi, 2007; Li et al., 2010b). Compared with hot mixture asphalt (HMA), CPAM has a special composition in which the binder is usually cutback asphalt or emulsified asphalt with low viscosity, poor initial strength, and cohesive properties in the early stage. Therefore, the material composition, such as type of binder, composition structure, and type of additive, can affect the interfacial bonding characteristics (Berlin and Hunt, 2001; Ferrotti et al., 2014; Ouyang et al., 2019b). Additionally, the external environment has an important influence on the interfacial bonding characteristics. In hot weather conditions, the viscosity of the tack coat decreases. Thus, the bonding between CPAM and the old pavement decreases. In contrast, the materials shrink in cold conditions, resulting in the expansion of the seam between CPAM and the old pavement (Ouyang et al., 2018). In a humid environment, moisture isolates CPAM and the old pavement, which reduces the interfacial bonding characteristics (Kuhn et al., 2005; Dong et al., 2014). Furthermore, the onsite construction treatment has some effects, such as compaction level, choice of tack coat, spreading amount of the tack coat, and the interface treatment method (Gómez-Meijide and Pérez, 2014). The above mentioned factors have different effects on the interfacial bonding performance (Ma et al., 2015). Choosing a tack coat with high viscosity and convenient construction may greatly improve the interfacial bonding performance. However, it is difficult to choose a suitable tack coat because there are many types of tack coat. In the actual construction process, the degree of compaction should generally meet the requirements, and the influence level is very small. This shows that the influencing factors of the interfacial bonding characteristics are complicated, so it is necessary to obtain a clear analysis of these factors.

Gray correlation analysis is very meaningful for the analysis of multiple complex influencing factors. The main problem solved by gray correlation analysis is finding a quantitative method that can measure the correlation between various factors in a system containing various factors in order to determine the main influencing factors (Julong, 1989; Zhang and Zhang, 2007). Gray correlation analysis has been used in various fields to analyze complex influencing factors, such as the study of the influence of asphalt surface properties on freezing viscosity strength (Zhang, 2013), effect of the crumb rubber modifier (CRM) content, CRM particle size, mixing time, and curing temperature on the viscosity of the crumb rubber-modified asphalt (Sun and Li, 2010) and evaluation of the shear performance of a flexible,

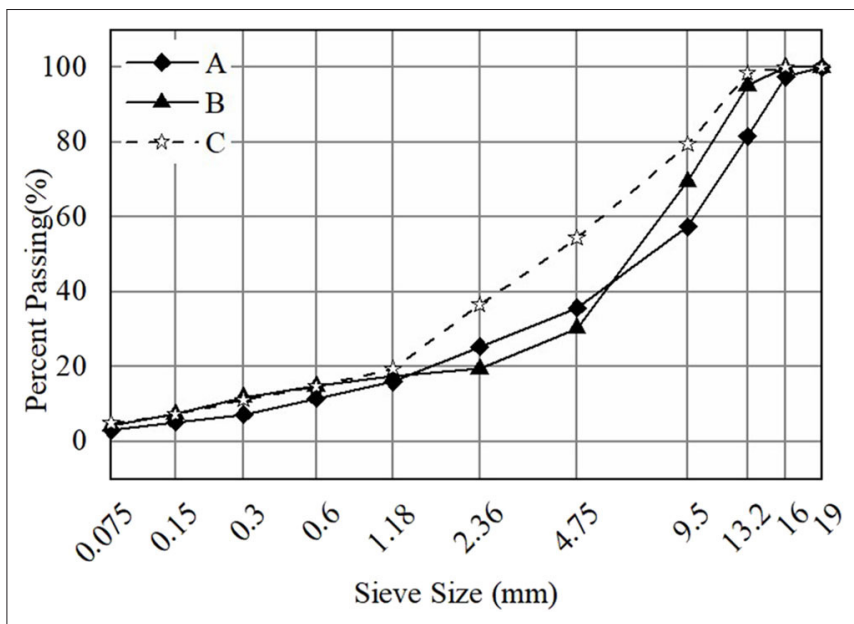

FIGURE 1 | Aggregate gradation for CPAM.

moisture proof-adhesive layer in a concrete bridge pavement base (Fen et al., 2009). Gray correlation analysis provides an opportunity to analyze the influencing factors of the interfacial bonding characteristics between CPAM and the old pavement.

In order to solve the above mentioned problems, in this work, the temperature, humidity, type of tack coat, amount of tack coat spreading, and surface roughness were taken as the influencing factors for the oblique shear test, and the influences of different factors on the interface bonding characteristics were analyzed. On this basis, a gray correlation analysis was performed to determine the degree of influence of each factor and to find the dominant factors. This analysis has a good guiding significance for the practical repair of potholes with CPAM.

\section{MATERIALS AND METHODS}

\section{Materials}

\section{Cold Patching Asphalt Mixture}

Three kinds of CPAM were selected for testing in the study. They were Changlin from China, Shell from Netherlands, and Maple from Canada, respectively, recorded as A, B, and C. Extraction and sieving of the three kinds of CPAM were performed to obtain a gradation curve, as shown in Figure 1. CPAM A contains less fine aggregate and more coarse aggregate, CPAM B contains more coarse and fine aggregate, and CPAM C contains more fine aggregate and less coarse aggregate.

\section{Tack Coat}

The tack coat was daubed onto the interface between the pothole and the old pavement before repair in order to wet the pothole so that CPAM could be well-bonded with the old pavement overall. Binders with different viscosities were chosen to make the test results obvious. From a wide variety of binders, modified emulsified asphalt A, modified emulsified asphalt B, SBS modified asphalt, matrix asphalt, and rubber asphalt were selected for this research. 


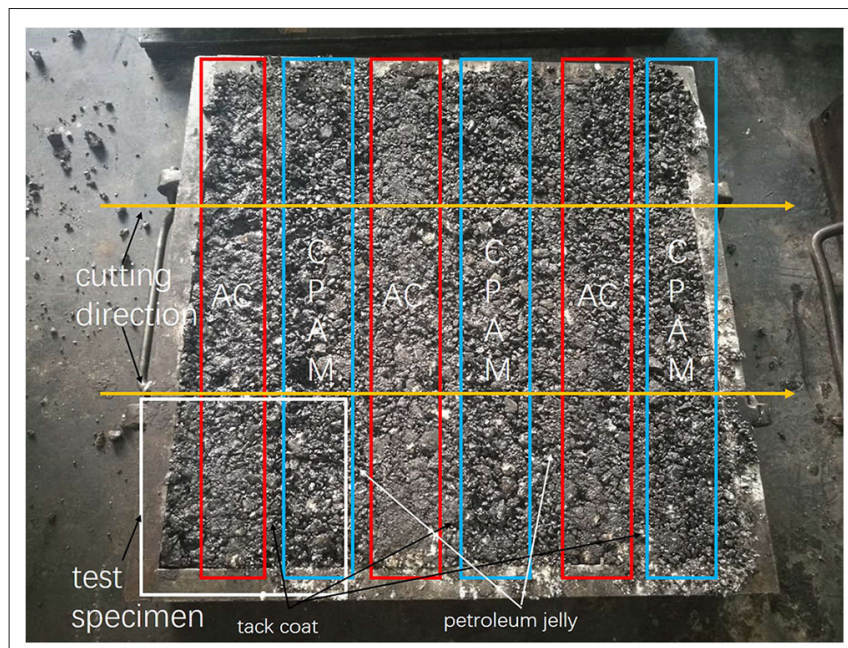

FIGURE 2 | The progress of specimen preparation.

\section{Experimental Methods Specimen Preparation}

The specimens used in the test were composite specimens composed of CPAM and HMA. The preparation process is as follows:

First, rutting specimens made of AC-13 with a size of $300 \mathrm{~mm}$ $\times 300 \mathrm{~mm} \times 50 \mathrm{~mm}$ were prepared. Second, they were cut into six trabeculae with a size of $300 \mathrm{~mm} \times 300 \mathrm{~mm} \times 50 \mathrm{~mm}$ and placed in the rutting specimen mold at $50-\mathrm{mm}$ interval, and the gap was filled with CPAM. The interface in one side was daubed with tack coat, and the interface in the other side was daubed with a paper sheet coated with petroleum jelly to prevent sticking. Then, after rolling the specimen 16 times, the specimen with the mold was put into an oven at $110^{\circ} \mathrm{C}$ for $24 \mathrm{~h}$, and then it was rolled again eight times, as shown in Figure 2. After the specimen had cooled, it was cut again. The interface between the CPAM and the original rutting specimen was well-bonded with the tack coat, and finally, specimens with a size of $100 \mathrm{~mm} \times 50 \mathrm{~mm} \times 100 \mathrm{~mm}$ for the oblique shear test were finished.

\section{Experimental Methods}

In this work, five factors were mainly studied: temperature, humidity, type of tack coat, amount of tack coat spreading, and interface roughness. In order to create the interface at a differently wet state, the specimens were immersed in moisture for different amounts of time. For the purpose of increasing the interface roughness, grooves were made on the surface at different intervals to increase the interface friction. The pendulum friction tester was used to determine the British pendulum number (BPN) value of the specimen surface in the direction of the groove (Karaca et al., 2013). For this test, a condition with temperature of $25^{\circ} \mathrm{C}$, no moisture immersion, tack coat of modified emulsified asphalt, spreading amount of $0.5 \mathrm{~kg} / \mathrm{m}^{2}$, and no grooving was used as the benchmark test condition. When studying the influence of a single factor on the interface bonding state, we kept the other conditions as per

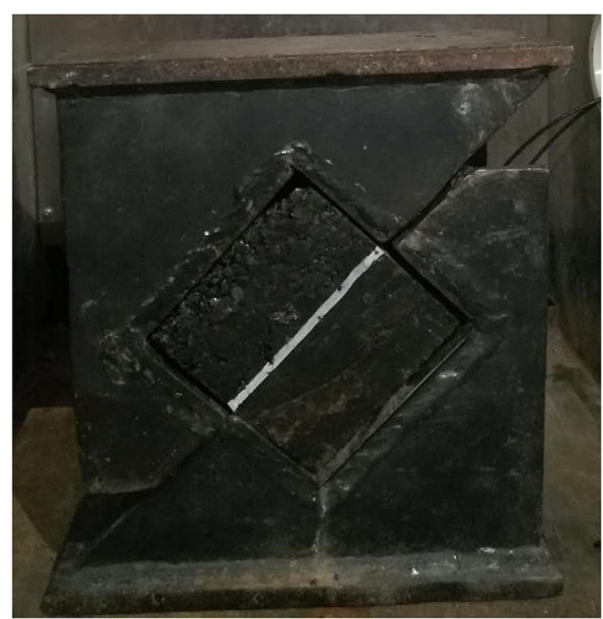

FIGURE 3 | The device of oblique shear test.

the benchmark test conditions and changed the single factor separately for research.

The oblique shear test was selected because it could accurately reflect the force state of the interface under the combined action of horizontal and vertical loads (Meng et al., 2018). The test device is shown in Figure 3. The size of the groove in the upper half was $100 \mathrm{~mm} \times 100 \mathrm{~mm} \times 50 \mathrm{~mm}$, with a slope of $45^{\circ}$. In order to reduce the influence of the horizontal force generated by the bottom friction on the test results, a roller coated with lubricant was placed under the mold. Finally, shear failure occurred for the interface.

\section{Gray Correlation Analysis of the Factors Influencing the Interfacial Bond Characteristics}

Gray correlation analysis was used to analyze the dominant influencing factors of multiple complex influencing factors (Wang et al., 2004) and to calculate the correlation degree in order to represent the importance of each influencing factor ( $\mathrm{Xu}$ and Yang, 2015). The specific steps are as follows:

(1) Define the subsequence $X$ and the parent sequence $Y$ : The influencing factors of the parameter indexes were seen as the subsequence $X$, where $X_{\mathrm{i}}$ was the value of the influencing factors such as the temperature. Correspondingly, the parameter index was taken as the parent sequence $Y$, where $Y_{\mathrm{i}}$ was the shear strength value corresponding to each influencing factor.

(2) Non-dimensionalization processing of the sequence factors: The interval-valued processing was used in this work, which was performed according to Equations (1) and (2).

$$
\begin{aligned}
x_{i j} & =\frac{x_{i j}-\min _{j} x_{i j}}{\max _{j} x_{i j}-\min _{j} x_{i j}} \\
x_{i j} & =\frac{y_{i j}-\min _{j} y_{i j}}{\max _{j} y_{i j}-\min _{j} y_{i j}}
\end{aligned}
$$


(3) Determine the matrix gray correlation difference information space: The difference sequence matrix was obtained with Equation (3). Then, the maximum values and the minimum values were obtained in the difference sequence matrix:

$$
\begin{array}{r}
\Delta_{i j}=\left|y_{i j}-x_{i j}\right| \\
\Delta_{\max }=\max \left(\Delta_{i j}\right) \\
\Delta_{\min }=\min \left(\Delta_{i j}\right)
\end{array}
$$

(4) Calculation of the parent association matrix and relevance: An overall analysis was performed to judge the differences and the correlations between the factors. Then, the correlation coefficient was used to represent the correlation coefficient matrix $L$ of the comparison factor and the reference factor, where each factor was determined with Equation (6):

$$
l_{i j}=\frac{\Delta_{\max }+\lambda \Delta_{\min }}{\Delta_{\max }+\Delta_{i j}}
$$

If there are too many correlation coefficients, the degree of information dispersion will be too large. Therefore, the average value of the correlation coefficient was used as a comparison index of the correlation degree of the influencing factors. The correlation between the various factors was obtained with Equation (7):

$$
r_{i}=\frac{1}{n} \sum \sum_{j=1}^{n} l_{i j}
$$

\section{RESULTS AND DISCUSSIONS}

The test results show that the failure of the specimens occurred at the interface between CPAM and HMA. The shear resistance at the interface is far less than that of the two materials themselves, indicating that the interface is the weak and easily damaged part after repair. The specific test results are shown in Table 1.

\section{Effect of Temperature on Interfacial Bonding Characteristics}

At the time of the research, most of the tack coat used between CPAM and the old pavement are asphalt materials. Due to the temperature sensitivity of the asphalt material, the interface between CPAM and the old pavement changes with different temperatures. Therefore, the effect of temperature on the interfacial bonding characteristics was investigated.

The oblique shear test results of three kinds of CPAM at different temperatures are shown in Figure 4. It can be seen that with the increase of temperature, the interface shear strength of the three kinds of CPAM gradually decreases. Taking CPAM A as an example, when the temperature increased from -5 to $55^{\circ} \mathrm{C}$, the interface shear strength decreased from 2.119 to $0.029 \mathrm{MPa}$, a reduction of $98.6 \%$. This is because the viscosity of the tack coat gradually decreases with increasing temperature, which results

\begin{tabular}{|c|c|c|c|c|}
\hline \multirow[t]{2}{*}{ Influencing factors } & \multirow[t]{2}{*}{ The levels of factors } & \multicolumn{3}{|c|}{ Shear strength (MPa) } \\
\hline & & A & B & C \\
\hline \multirow[t]{5}{*}{ Temperature $/{ }^{\circ} \mathrm{C}$} & -5 & 2.119 & 2.323 & 2.763 \\
\hline & 10 & 1.237 & 1.361 & 1.497 \\
\hline & 25 & 0.478 & 0.503 & 0.563 \\
\hline & 40 & 0.043 & 0.154 & 0.089 \\
\hline & 55 & 0.029 & 0.059 & 0.049 \\
\hline \multirow[t]{5}{*}{ Humidity } & 0 & 0.478 & 0.503 & 0.563 \\
\hline & $12 \mathrm{~h}$ & 0.314 & 0.382 & 0.431 \\
\hline & $24 \mathrm{~h}$ & 0.194 & 0.262 & 0.311 \\
\hline & $36 \mathrm{~h}$ & 0.146 & 0.189 & 0.217 \\
\hline & $48 \mathrm{~h}$ & 0.099 & 0.123 & 0.155 \\
\hline \multirow[t]{5}{*}{ Types of tack coat } & Matrix asphalt & 0.313 & 0.310 & 0.286 \\
\hline & $\begin{array}{l}\text { Modified emulsified } \\
\text { asphalt B }\end{array}$ & 0.445 & 0.454 & 0.430 \\
\hline & $\begin{array}{l}\text { Modified emulsified } \\
\text { asphalt A }\end{array}$ & 0.478 & 0.503 & 0.563 \\
\hline & SBS modified asphalt & 0.406 & 0.372 & 0.312 \\
\hline & Rubber asphalt & 0.347 & 0.358 & 0.325 \\
\hline \multirow{5}{*}{$\begin{array}{l}\text { The amount of tack } \\
\text { coat spreading } / \mathrm{kg} / \mathrm{m}^{2}\end{array}$} & 0 & 0.228 & 0.293 & 0.409 \\
\hline & 0.25 & 0.262 & 0.356 & 0.530 \\
\hline & 0.5 & 0.478 & 0.503 & 0.563 \\
\hline & 0.75 & 0.505 & 0.496 & 0.471 \\
\hline & 1 & 0.516 & 0.470 & 0.435 \\
\hline \multirow[t]{5}{*}{ Surface roughness } & No groove & 0.478 & 0.503 & 0.563 \\
\hline & $2 \mathrm{~cm}$ & 0.547 & 0.577 & 0.650 \\
\hline & $1.5 \mathrm{~cm}$ & 0.585 & 0.626 & 0.694 \\
\hline & $1 \mathrm{~cm}$ & 0.600 & 0.647 & 0.718 \\
\hline & $0.5 \mathrm{~cm}$ & 0.609 & 0.658 & 0.731 \\
\hline
\end{tabular}
in the decrease of the bonding ability of CPAM with the old pavement. This indicates that temperature has a significant effect on the interfacial adhesion strength.
TABLE 1 | Results of the oblique shear test under different influencing factors.

Before the temperature reached $40^{\circ} \mathrm{C}$, the interface shear strength decreased rapidly for the three kinds of CPAM, but after $40^{\circ} \mathrm{C}$, it became very low and remained essentially unchanged. Taking CPAM A as an example, when the temperature rises from -5 to $40^{\circ} \mathrm{C}$, the shear strength decreases from 2.119 to $0.043 \mathrm{MPa}$, which is a reduction of $98 \%$. This is mainly because of an essential feature of asphalt that decreases with increasing temperature. However, when the viscosity of the tack coat is very low and basically unchanged with the temperature increase, the tack coat fails to adhere to CPAM and the old pavement. Unlike the asphalt wrapped on the surface of the aggregate, the failure temperature of the interface is lower. From the above mentioned analysis, it can be seen that the failure temperature is about $40^{\circ} \mathrm{C}$.

Through the data fitting of the shear strength at different temperatures, the functional relationship between temperature and bonding degree was summarized, as shown in Figure 5. The equation is a binomial function, $y=2.06-6.983 \times$ $10^{-2} x-2.71 \times 10^{-4} x^{2}+2.97 \times 10^{-5} x^{3}-2.72 \times 10^{-7} x^{4}$, $R^{2}=0.97874$. It can be seen that the fitting effect is good. 


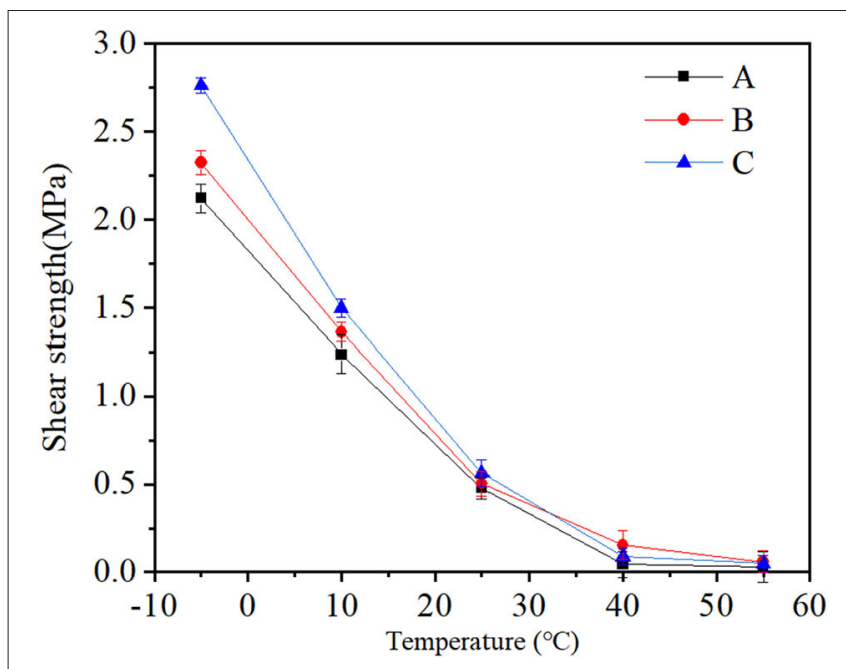

FIGURE 4 | Interfacial shear strength at different temperatures.

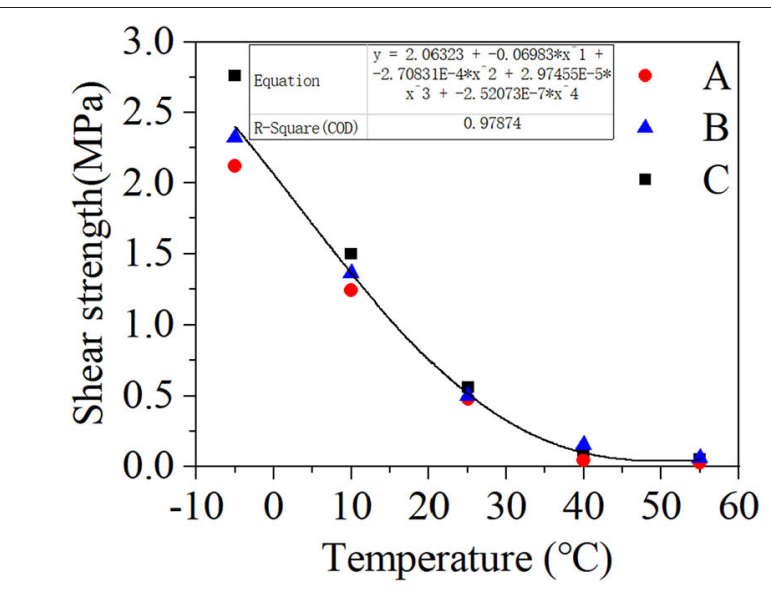

FIGURE 5 | The functional relationship between temperature and bonding degree.

This equation can predict the interface bonding strength at different temperatures and guide the construction process of pothole repair.

\section{Effect of Humidity on Interfacial Bonding Characteristics}

When the moisture penetrates the interface between CPAM and the old pavement, the dynamic water pressure that is generated with intermittent dynamic vehicle easily breaks the interface, so it is necessary to study the influence of different humidities on the interface bonding characteristics.

The interfacial shear strength results for different humidities are shown in Figure 6. It can be seen that the longer the immersion time is, the lower the interfacial shear strength is. Taking CPAM C as an example, after the moisture immersion time increased from 0 to $48 \mathrm{~h}$, the interface shear strength decreased from 0.563 to $0.155 \mathrm{MPa}$, a decrease of $72.5 \%$. This

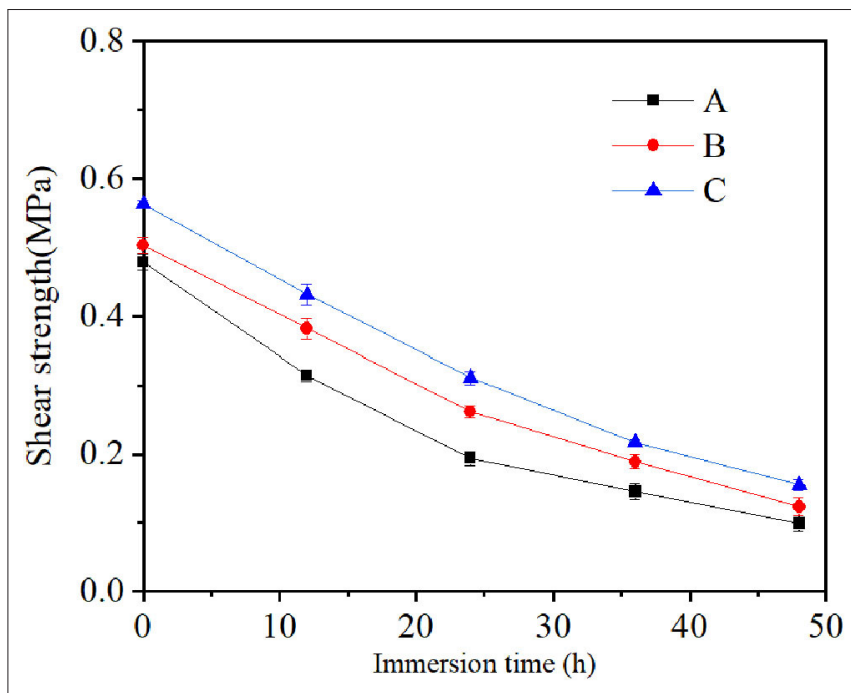

FIGURE 6 | Interfacial shear strength at different humidity.

indicates that as the moisture immersion time increases, moisture infiltrates into the interface and acts as a lubricant, which causes an obvious reduction in the interface bonding strength. Therefore, it is necessary to drain the water in the pothole and keep it dry before repair.

\section{Effect of Types of Tack Coat on Interfacial Bonding Characteristics}

Considering the different viscosities of the different tack coats, five kinds of tack coat (matrix asphalt, modified emulsified asphalt A, modified emulsified asphalt B, SBS-modified asphalt, and rubber asphalt) were selected to study the influence of the interface characteristics. Dynamic viscosity tests at $60^{\circ} \mathrm{C}$ were performed on five kinds of asphalt or their evaporation residues. The order of the viscosity was as follows: modified emulsified asphalt $\mathrm{A}>$ modified emulsified asphalt $\mathrm{B}>$ SBS-modified asphalt $>$ rubber asphalt $>$ matrix asphalt.

The interface shear strengths of the different tack coats are shown in Figure 7. For the three kinds of CPAM, the shear strength of the five binders is in the same order. Taking CPAM A as an example, when matrix asphalt, modified emulsified asphalt B, modified emulsified asphalt A, SBS-modified asphalt, and rubber asphalt are used as tack coat, their shear strengths are $0.313,0.445,0.478,0.406$, and $0.347 \mathrm{MPa}$, respectively. It can be known from this information that the greater the viscosity of the binder is, the stronger the interfacial shear strength is. Therefore, when CPAM is used to repair a pothole, a tack coat with high viscosity should be selected.

\section{Effect of Tack Coat Spreading on Interfacial Bonding Characteristics}

The results of the interfacial shear strength at different amounts of tack coat spreading are shown in Figure 9. It can be seen that with the increase of binder amounts, the interfacial shear strength of CPAM B and CPAM C climbs up and then declines, 


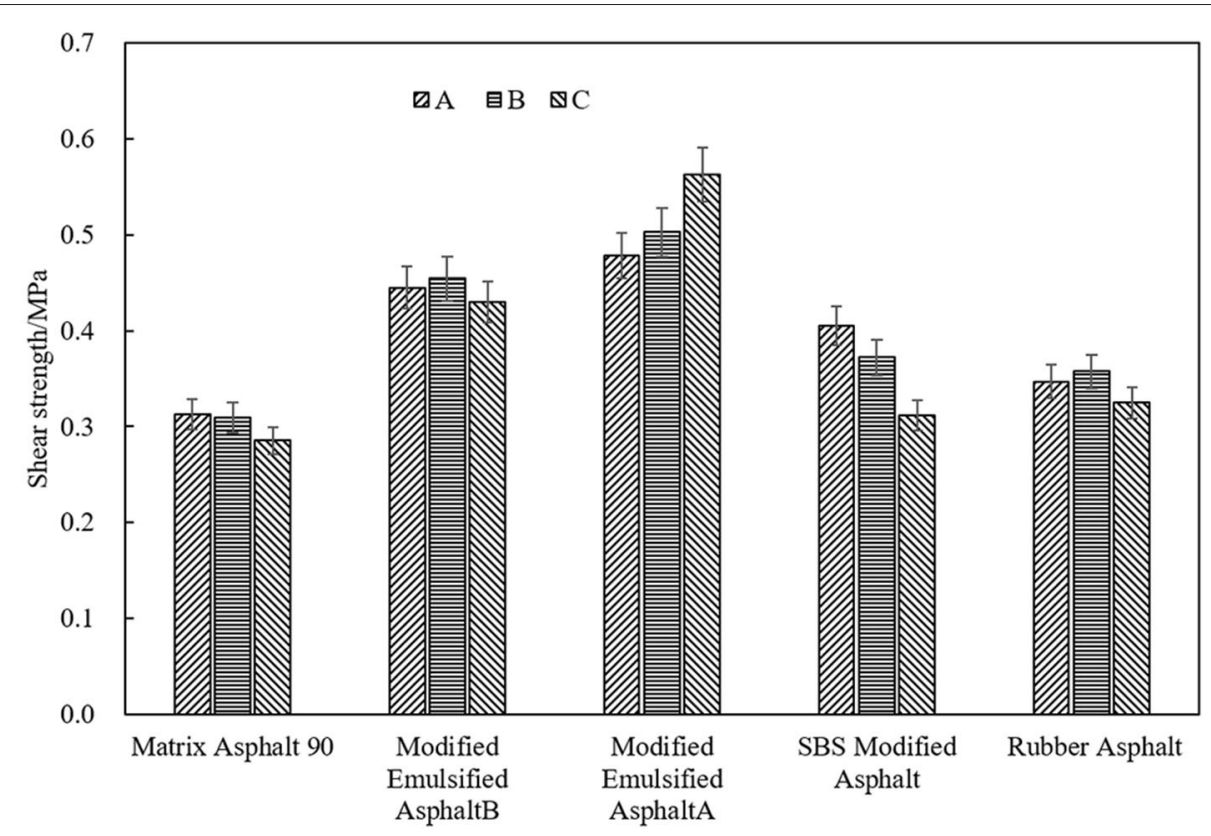

FIGURE 7 | Interfacial shear strength at different tack coat.

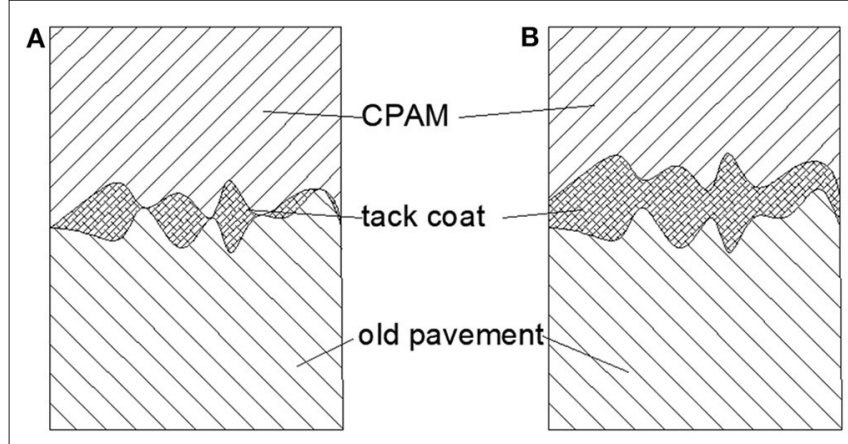

FIGURE 8 | The tack coat between CPAM and old pavement.

and the maximum shear strengths are obtained at 0.75 and 0.5 $\mathrm{kg} / \mathrm{m}^{2}$, respectively. For CPAM A, the shear strength increases, but after the spreading amount becomes $0.5 \mathrm{~kg} / \mathrm{m}^{2}$, the shear strength generally does not increase. It can be known that there is an optimal spreading amount of tack coat for CPAM B and CPAM $\mathrm{C}$ to repair the pothole. Although the optimal spreading amount for CPAM A does not appear in the figure because of the limitation of the spreading amount range in the test, it can be concluded from the curve trend that there is an optimal spreading amount after the spreading amount of $1 \mathrm{~kg} / \mathrm{m}^{2}$. This happens because, at the beginning, with the increase of tack coat spreading amount, the tack coat fills in the gap between CPAM and the old pavement, bonding them together. However, after the spreading amount reaches a certain level, the interfacial voids are filled up, and the excess adhesive acts as a lubricant, so the interface shear strength decreases (Figure 8).

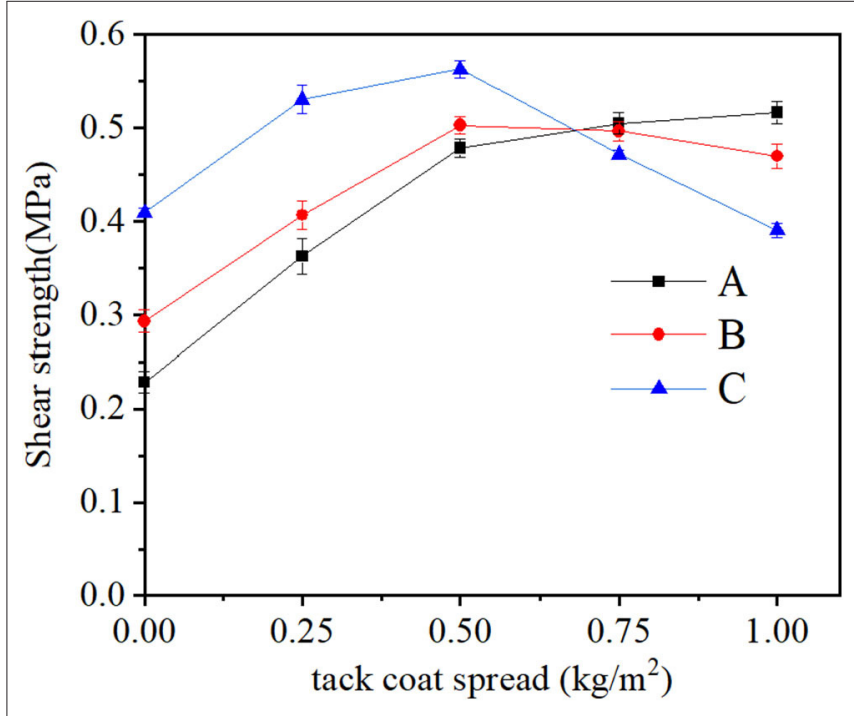

FIGURE 9 | Interfacial shear strength at different tack coat spreading amount.

It can also be seen from Figure 9 that the optimal spreading amounts for CPAM A, CPAM B, and CPAM C are $>1,0.75$, and $0.5 \mathrm{~kg} / \mathrm{m}^{2}$, respectively. This is determined by the void structure of CPAM. CPAM C has high fine aggregate content, low air void content, and low tack coat capacity, so the optimal spreading amount is the smallest. CPAM A has high coarse aggregate content, high air void content, and high tack coat capacity, so the optimal spreading amount is the largest. Therefore, the tack coat spreading amount is greater for CPAM with large voids. 


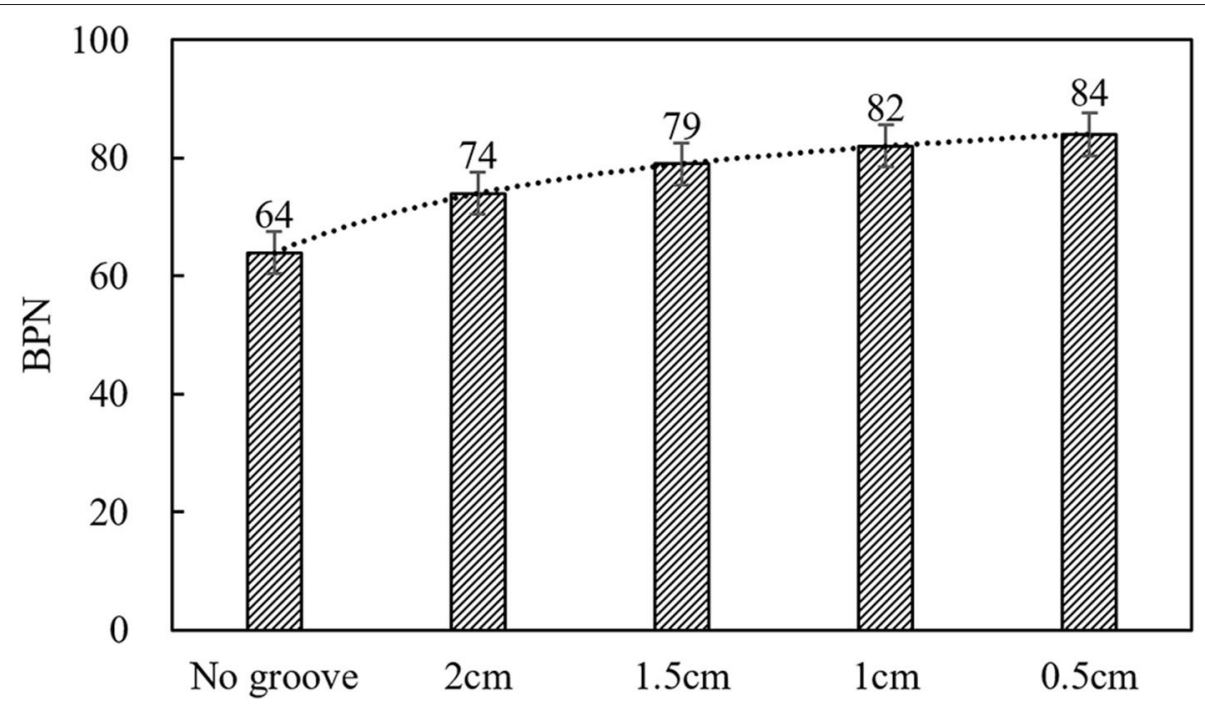

FIGURE 10 | Relation between groove interval and BPN value.

\section{Effect of Roughness Interfacial Bonding Characteristics}

Due to the different roughness levels of the interface, the contact area between the tack coat and the interface is different. Thus, the interface adhesion characteristics are also different. Therefore, the influence of different surface roughness on the surface bonding characteristics was studied in this work.

In order to increase the roughness of the surface, some grooves were made in the surface of HMA at intervals of $0.5,1,1.5$, and $2 \mathrm{~cm}$, respectively. The pendulum friction meter was used to measure the BPN value of the surface perpendicular to the groove direction, as shown in Figure 10. It can be seen that the BPN value increases with the decrease of groove spacing. When the groove interval is $0.5 \mathrm{~cm}$, the $\mathrm{BPN}$ is 84 , and when not grooved, the BPN is 64, which is an increase of $31.3 \%$. Therefore, by grooving on the surface of the old pavement, the roughness increases, and the roughness increases with the decrease of the groove interval. As the groove interval decreases, the increase rate of the BPN value gradually slows down. When the groove interval is $1 \mathrm{~cm}$, the $\mathrm{BPN}$ is 82 . When the groove interval is closer to $0.5 \mathrm{~cm}$, the BPN is 84 , increasing by only $2.4 \%$. It can be seen that when the interval of the grooves is small to a certain extent, the grooves have little effect on increasing the roughness. The shear strength at different roughness levels is shown in Figure 11. With the increase of the BPN value, the shear strength gradually increases, and when the BPN reaches 82 , that is, when the optimal groove spacing is $1 \mathrm{~cm}$, the shear strength reaches a maximum and then decreases. The reason for this phenomenon is that there is a competitive relationship between the tack coat in the groove and the tack coat on the interface, as shown in Figure 12. The tack coat at the interface can preferentially penetrate into the groove, increasing the contact bonding area, and at the same time, the tack coat acts as an anchor. Therefore, the smaller the groove spacing in a certain range, the greater the shear strength is. However, when the interval between the grooves is too small, with

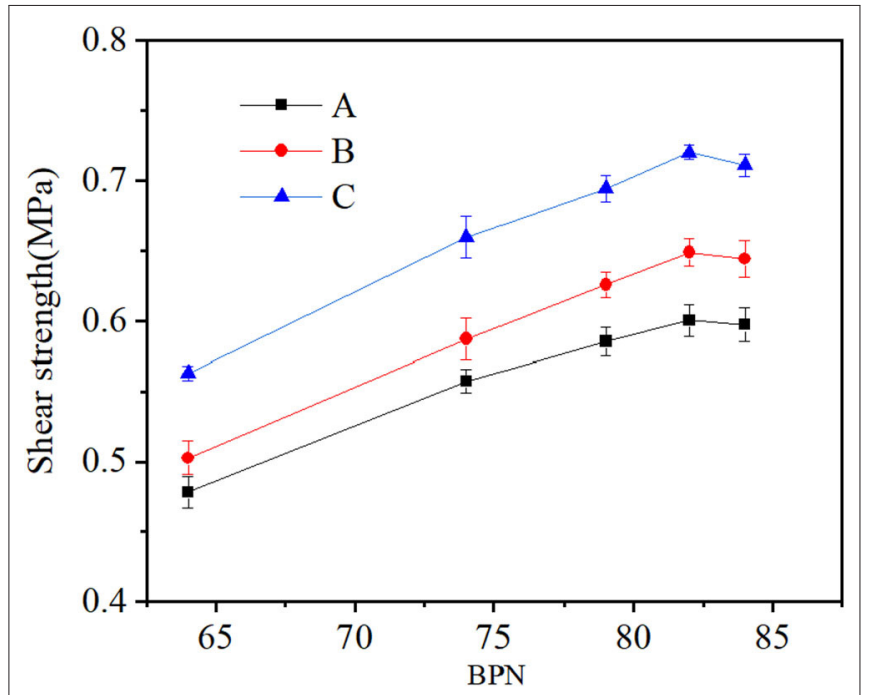

FIGURE 11 | Interfacial shear strength at different surface roughness.

too many grooves, more tack coat penetrates into the grooves, resulting in an insufficient tack coat amount at the interface, so the shear strength is reduced. It can be known that if the groove interval is small, reaching a certain level, the interface bonding strength will reduce. Therefore, it should be noted that the groove interval has to be appropriate.

\section{Gray Correlation Analysis of Factors Affecting Interfacial Bonding Characteristics}

Taking the shear strength as the parent sequence and each influencing factor value as the subsequence, the correlation degrees of different influencing factors on the shear strength were 


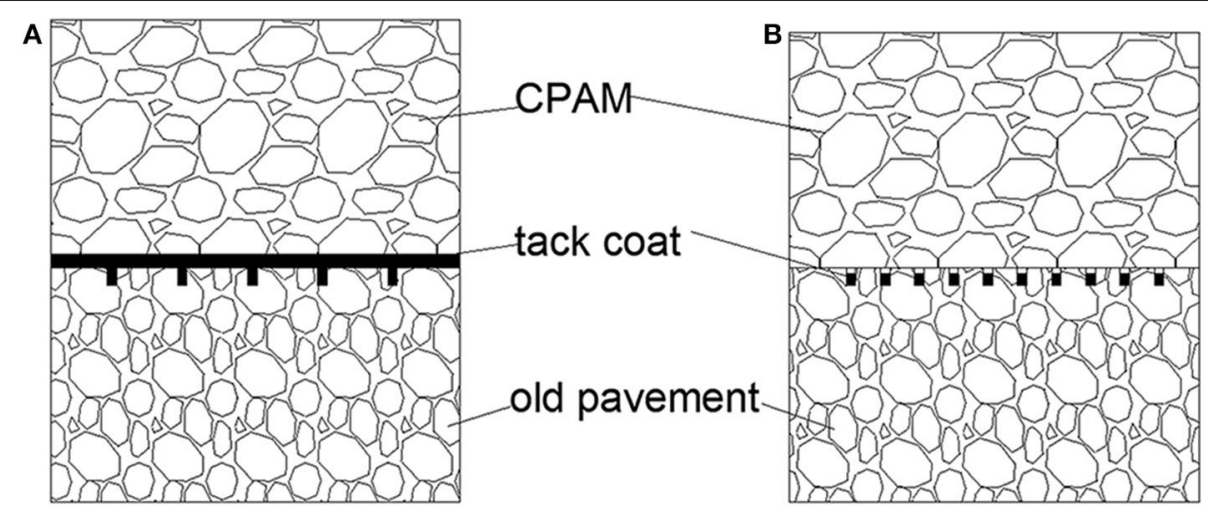

FIGURE 12 | Competitive relationship of the tack coat between the groove and the interface.

TABLE 2 | Gray correlation degree between the different influencing factors and shear strength.

\begin{tabular}{|c|c|c|c|c|c|}
\hline Factors & Temperature & Humidity & Types of tack coat & $\begin{array}{l}\text { Amount of } \\
\text { tack coat } \\
\text { spreading }\end{array}$ & Surface roughness \\
\hline$A$ & 0.462 & 0.478 & 0.874 & 0.796 & 0.87 \\
\hline B & 0.462 & 0.491 & 0.93 & 0.717 & 0.897 \\
\hline C & 0.465 & 0.494 & 0.889 & 0.553 & 0.879 \\
\hline
\end{tabular}

obtained through gray correlation analysis. A greater correlation degree indicates that the influence of the factor on the interface bonding characteristics is greater. In contrast, the smaller the correlation degree is, the less the influence this factor has on the interface bonding characteristics. The correlation degree between the different influencing factors and the shear strength was calculated using Equations (1)-(7). The results are shown in Table 2.

The gray correlation degrees between the different influencing factors of the three kinds of CPAM and the shear strength are shown in Figure 13. It can be seen that the correlation degrees of the different factors with the three kinds of CPAM are not very different, which shows that the influence of each factor on the interfacial bonding characteristics has little correlation with the type of CPAM. Among all of the factors, the most relevant factor for shear strength is the type of tack coat, for which the gray correlation degrees in these three kinds of CPAM were up to $0.874,0.93$, and 0.889 , that is, the type of tack coat has the greatest influence on the interface bonding characteristics. The gray correlation degrees between the interface roughness and the shear strength are $0.87,0.897$, and 0.879 . There are only differences of $0.004,0.033$, and 0.01 from the values of the tack coat. Therefore, both the tack coat and the roughness of the interface have a high degree of influence on the interface bonding characteristics. In comparison, the correlation degrees between temperature and shear strength are the smallest, being 0.462 , 0.462 , and 0.465 . Therefore, temperature has the least influence on the interface bonding characteristics. The correlation degrees between humidity and shear strength are $0.478,0.491$, and 0.494 , with differences of only $0.016,0.029$, and 0.029 from those of temperature. Therefore, the influence of temperature and humidity on the interface bonding characteristics is relatively small. In summary, the order of the influence degrees of different influencing factors on the interfacial bonding characteristics is as follows: type of tack coat $>$ interface roughness $>$ amount of tack coat spreading $>$ humidity $>$ temperature. The dominant factors that affect the interface adhesion characteristics are the type of tack coat and the roughness of the interface. The type of tack coat and the interface roughness affect the interface bonding characteristics more than temperature and humidity do, that is, the external environment has a smaller degree of influence on the interface bonding characteristics than the type of material and the construction process do. Therefore, in the actual repair of potholes, attention should be paid to the choice of the type of tack coat, and the surface roughness should be increased in some methods to improve the interface bonding characteristics.

\section{CONCLUSIONS}

In this work, three kinds of CPAM were used to study the effects of five factors, including temperature, humidity, type of tack coat, amount of tack coat spreading, and interface roughness, on the interface bonding characteristics between CPAM and the old pavement. Finally, the influence degree of the different influencing factors on the interface bonding characteristics was clarified through gray correlation analysis, and the following conclusions were drawn.

First, as the temperature increases, the bonding performance at the interface gradually decreases. The functional relationship 


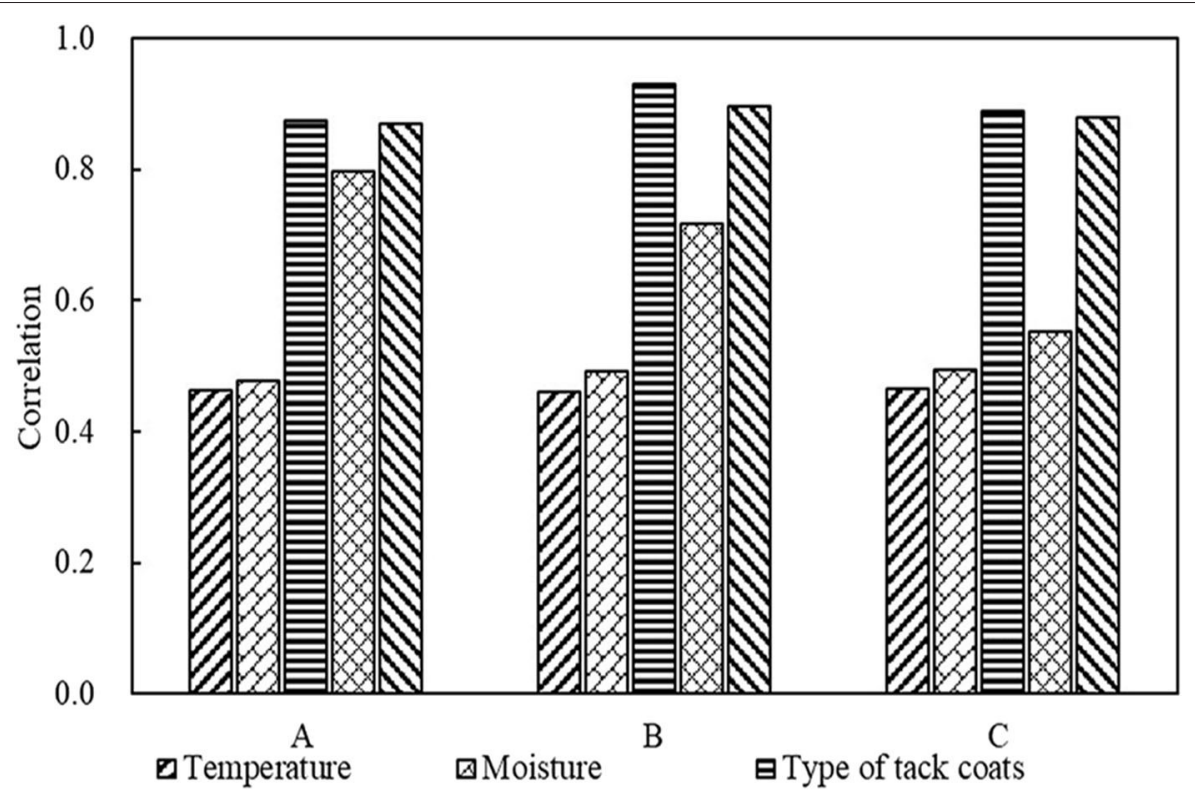

$\nabla$ Spread of tack coats $\Delta$ Surface roughness

FIGURE 13 | The gray correlation degree.

between temperature and bonding degree is $y=2.06-6.983$ $\times 10^{-2} x-2.71 \times 10^{-4} x^{2}+2.97 \times 10^{-5} x^{3}-2.72 \times 10^{-7} x^{4}$, and the interface failure temperature is about $40^{\circ} \mathrm{C}$. The interface bonding strength gradually decreases with increasing humidity.

Second, there is an optimal spreading amount for the tack coat, and the denser the CPAM is, the smaller the optimal spreading amount is. The cutting grooves on the old pavement can increase the interface shear strength, and the smaller the spacing of the grooves within a certain range is, the greater the shear strength is. However, due to the competitive relationship between the tack coat penetrating into the groove and the tack coat remaining on the surface, when the groove intervals are too small, reaching a certain level, the interfacial bonding strength decreases. The optimal groove spacing is considered to be $1 \mathrm{~cm}$.

Finally, the influence degree order of the five influencing factors on the bonding of the interface is as follows: type of tack coat $>$ interface roughness $>$ amount of tack coat spreading $>$ humidity $>$ temperature, and the dominant influencing factors of the interface bonding performance are the type of tack coat and the interface roughness. Therefore, in the actual repair of potholes, attention should be paid to the selection of the type of tack coat and the control of the tack coat spreading amount. Additionally, the surface roughness can be

\section{REFERENCES}

Adlinge, S. S., and Gupta, A. K. (2013). Pavement deterioration and its causes. Int. J. Innov. Res. Dev. 2, 437-450. Available online at: http://www.iosrjournals.org/ iosr-jmce/papers/sicete(civil)-volume6/60.pdf

Anderson, D. A., Thomas, H. R., Siddiqui, Z., and Krivohlavek, D. (1998). More Effective Cold, Wet-Weather Patching Materials for Asphalt Pavements. Report No. FHWA-RD-88-001. Federal Highway Administration, Washington, DC. increased by grooving or brushing to improve the interface bonding characteristics.

\section{DATA AVAILABILITY STATEMENT}

All datasets generated for this study are included in the article/supplementary material.

\section{AUTHOR CONTRIBUTIONS}

YT and FC provided the research direction and funding as well as equipment support. KL and SY were responsible for testing, simulation, and writing of the manuscript. HX and JO provided the detailed ideas and suggestions for the research. All authors contributed to the article and approved the submitted version.

\section{ACKNOWLEDGMENTS}

The authors would like to acknowledge the financial support of the Civil Aviation Administration of China. Meanwhile, the authors would like to acknowledge the test equipment supported by the School of Transportation Science and Engineering, Harbin Institute of Technology.

Berlin, M., and Hunt, E. (2001). Asphalt Concrete Patching Material Evaluation: Interim Report (No. OR-RD-01-15). Austin, TX: Oregon Department of Transportation Research Unit.

Diaz, L. G. (2016). Creep performance evaluation of Cold Mix Asphalt patching mixes. Int. J. Pavement Res. Techn. 9, 149-158. doi: 10.1016/j.ijprt.2016. 04.002

Dong, Q., Huang, B., and Jia, X. (2014). Long-term costeffectiveness of asphalt pavement pothole patching 
methods. Transp. Res. Rec. 2431, 49-56. doi: 10.3141/ 2431-07

Fen, Y., Kong, Z., Xiao-yang, J., Qing-qing, L., and Jun, Y. (2009). Evaluation of shear performance of flexible waterproof-adhesive layer in concrete bridge pavement based on grey correlation analysis. Road Mater. Pavement Design 10, 349-360. doi: 10.1080/14680629.2009.9690251

Ferrotti, G., Pasquini, E., and Canestrari, F. (2014). Experimental characterization of high-performance fiber-reinforced cold mix asphalt mixtures. Construct. Build. Mater. 57, 117-125. doi: 10.1016/j.conbuildmat.2014.01.089

Gómez-Meijide, B., and Pérez, I. (2014). Effects of the use of construction and demolition waste aggregates in cold asphalt mixtures. Constr. Build. Mater. 51, 267-277. doi: 10.1016/j.conbuildmat.2013.10.096

Julong, D. (1989). Introduction to grey system theory. J. Grey Syst. 1, 1-24.

Karaca, Z., Gürcan, S., Gökçe, M. V., and Sivrikaya, O. (2013). Assessment of the results of the pendulum friction tester (EN 14231) for natural building stones used as floor-coverings. Constr. Build. Mater. 47, 1182-1187. doi: 10.1016/j.conbuildmat.2013.06.011

Kim, K., Kim, S. H., and Kim, N. (2017). A study on algorithm for materials take-off using pothole detection system. J. Korean Soc. Civil Eng. 37, 603-610. doi: 10.12652/Ksce.2017.37.3.0603

Kim, T., and Ryu, S. K. (2014). Review and analysis of pothole detection methods. J. Emerg. Trends Comp. Inform. Sci. 5, 603-608. Available online at: http://www. cisjournal.org/journalofcomputing/archive/vol5no8/vol5no8_3.pdf

Kuhn, E. A., Papagiannakis, A. T., and Loge, F. J. (2005). Preliminary analysis of the impact of cold mix asphalt concretes on air and water quality. Bull. Environ. Contam. Toxicol. 74, 501-508. doi: 10.1007/s00128-00 5-0613-3

Li, F., Huang, S., Xu, J., and Qin, Y. (2010b). Performance evaluation and technical requirements of cold patch asphalt mixture. J. Tongji Univ. Nat. Sci. 10. doi: 10.3969/j.issn.0253-374x.2010.10.011

Li, F., Huang, S. C., Xu, J., and Qin, Y. C. (2010a). Research on composition design of cold patch asphalt mixture. J. Wuhan Univ. Techn. 14. doi: 10.3963/j.issn.1671-4431.2010.14.018

Liao, M. C., Luo, C. C., Wang, T. Y., and Xie, X. (2016). Developing effective test methods for evaluating cold-mix asphalt patching materials. J. Mater. Civil Eng. 28:04016108. doi: 10.1061/(ASCE)MT.1943-5533.0001639

Ma, T., Wang, H., Zhao, Y., Huang, X., and Pi, Y. (2015). Strength mechanism and influence factors for cold recycled asphalt mixture. Adv. Mater. Sci. Eng. 2015:181853. doi: 10.1155/2015/181853

Meng, B., Jing, H., Yang, S., Wang, Y., and Li, B. (2018). Experimental study on the shear behavior of bolted concrete blocks with oblique shear test. Adv. Civil Eng. 2018, 1-8. doi: 10.1155/2018/7281218

Munyagi, A. A. (2007). Evaluation of cold asphalt patching mixes (Ph.D. dissertation). University of Stellenbosch, Stellenbosch, South Africa.

Ouma, Y. O., and Hahn, M. (2017). Pothole detection on asphalt pavements from 2D-colour pothole images using fuzzy c-means clustering and morphological reconstruction. Automat. Constr. 83, 196-211. doi: 10.1016/j.autcon.2017.08.017

Ouyang, J., Hu, L., Yang, W., and Han, B. (2019a). Strength improvement additives for cement bitumen emulsion mixture. Constr. Build. Mater. 198, 456-464. doi: 10.1016/j.conbuildmat.2018.11.280

Ouyang, J., Pan, B., Xu, W., and Hu, L. (2019b). Effect of water content on volumetric and mechanical properties of cement bitumen emulsion mixture. J. Mater. Civil Eng. 31:04019085. doi: 10.1061/(ASCE)MT.1943-5533.0002736

Ouyang, J., Yang, W., Chen, J., and Han, B. (2020). Effect of superplasticizer and wetting agent on pavement properties of cold recycled mixture with bitumen emulsion and cement. J. Mate. Civil Eng. 32:04 020136. doi: 10.1061/(ASCE)MT.1943-5533.0003194
Ouyang, J., Zhao, J., and Tan, Y. (2018). Modeling mechanical properties of cement asphalt emulsion mortar with different asphalt to cement ratios and temperatures. J. Mater. Civil Eng. 30:04018263. doi: 10.1061/(ASCE)MT.1943-5533.0002480

Prowell, B. D., and Franklin, A. G. (1996). Evaluation of cold mixes for winter pothole repair. Transp. Res. Rec. 1529, 76-85. doi: 10.1177/0361198196152900110

Rezaei, M., Hashemian, L., Bayat, A., and Huculak, B. (2017). Investigation of rutting resistance and moisture damage of cold asphalt mixes. J. Mater. Civil Eng. 29:04017193. doi: 10.1061/(ASCE)MT.1943-5533.0002042

Rosales Herrera, V. I., and Prozzi, J. A. (2008). Mixture Design Manual and Performance-Based Specifications for Cold Patching Mixtures (No. Report No. 0-4872-P2). Salem: Center for Transportation Research, University of Texas at Austin.

Sun, D. Q., and Li, L. H. (2010). Factors affecting the viscosity of crumb rubber-modified asphalt. Pet. Sci. Technol. 28, 1555-1566. doi: 10.1080/10916466.2010.497007

Tan, Y., Zhou, S., Shan, L., and Chen, Z. (2014). Optimization design and study on properties of anti-freezing cold patch asphalt mixture. J. Build. Mater. 17, 89-94. doi: 10.3969/j.issn.1007-9629.2014.01.016

Tedeschi, A., and Benedetto, F. (2017). A real-time automatic pavement crack and pothole recognition system for mobile Android-based devices. Adv. Eng. Inform. 32, 11-25. doi: 10.1016/j.aei.2016.12.004

Wang, H. W., Chen, C. H., Cheng, D. Y., Lin, C. H., and Lo, C. C. (2015). A realtime pothole detection approach for intelligent transportation system. Math. Probl. Eng. 2015, 1-7. doi: 10.1155/2015/813507

Wang, Y., Yin, K. L., and An, G. F. (2004). Grey correlation analysis of sensitive factors of landslide. Rock Soil Mech. 25, 91-93. doi: 10.3969/j.issn.1000-7598.2004.01.019

Xu, G., and Yang, Z. (2015). Multiobjective optimization of process parameters for plastic injection molding via soft computing and grey correlation analysis. Int. J. Adv. Manuf. Techn. 78, 525-536. doi: 10.1007/s00170-014-6643-4

Zhang, Y., and Zhang, X. (2007). Grey correlation analysis between strength of slag cement and particle fractions of slag powder. Cem. Concrete Comp. 29, 498-504. doi: 10.1016/j.cemconcomp.2007.02.004

Zhang, Z. (2013). Study on the factors influencing the freezing adhesion strength of asphalt materials (Ph.D. thesis). Chang'an University, Xi'an, China.

Zhang, Z., Ai, X., Chan, C. K., and Dahnoun, N. (2014). "An efficient algorithm for pothole detection using stereo vision," in 2014 IEEE International Conference on Acoustics, Speech and Signal Processing, ICASSP (Florence: IEEE), 564-568.

Zhao, L. D., and Tan, Y. Q. (2010). A summary of cold patch material for asphalt pavements. Adv. Mat. Res. 168-170, 864-869. doi: 10.4028/www.scientific.net/AMR.168-170.864

Conflict of Interest: FC, KL, and SY was employed by the company China Airport Construction Group Corporation and Beijing Super-Creative Technology Co., Ltd.

The remaining authors declare that the research was conducted in the absence of any commercial or financial relationships that could be construed as a potential conflict of interest.

Copyright (C) 2020 Chen, Liu, Tan, Ye, Xu and Ouyang. This is an open-access article distributed under the terms of the Creative Commons Attribution License (CC BY). The use, distribution or reproduction in other forums is permitted, provided the original author(s) and the copyright owner(s) are credited and that the original publication in this journal is cited, in accordance with accepted academic practice. No use, distribution or reproduction is permitted which does not comply with these terms. 